\title{
A Grounded Theory Analysis Of E-Collaboration EfFectS For Distributed Project MANAGement
}

\author{
S. Qureshi, M. Liu and D. Vogel
}

\begin{tabular}{|l|l|}
\hline \multicolumn{2}{|l|}{ ERIM REPORT SERIES RESEARCH IN MANAGEMENT } \\
\hline ERIM Report Series reference number & ERS-2004-059-LIS \\
\hline Publication & June 2004 \\
\hline Number of pages & 28 \\
\hline Email address corresponding author & squreshi@mail.unomaha.edu \\
\hline Address & Erasmus Research Institute of Management (ERIM) \\
& Rotterdam School of Management / Rotterdam School of \\
& Economics \\
& Erasmus Universiteit Rotterdam \\
& P.O. Box 1738 \\
& 3000 DR Rotterdam, The Netherlands \\
& Phone: +31 10 408 1182 \\
& Fax: +31 10 408 9640 \\
& Email: info@erim.eur.nl \\
& Internet: www.erim.eur.nl \\
\hline
\end{tabular}

Bibliographic data and classifications of all the ERIM reports are also available on the ERIM website: www.erim.eur.nl 


\title{
ERASMUS RESEARCH INSTITUTE OF MANAGEMENT
}

\author{
REPORT SERIES \\ RESEARCH IN MANAGEMENT
}

\begin{tabular}{|c|c|c|}
\hline \multicolumn{3}{|c|}{ BIBLIOGRAPHIC DATA AND CLASSIFICATIONS } \\
\hline Abstract & \multicolumn{2}{|c|}{$\begin{array}{l}\text { The emergence and widespread use of collaborative technologies for distributed project } \\
\text { management has brought opened up a myriad of opportunities for business. While the } \\
\text { opportunities for off-shore outsourcing and collaborative development are enticing, most tools } \\
\text { and techniques for project management focus on on-site, long term relationships and sourcing } \\
\text { strategies at a time when inter-organizational relationships are becoming dynamic and } \\
\text { temporary. This paper uses grounded theory to analyze data on virtual teams. The analysis } \\
\text { uncovers "effects" in the way distributed projects are managed. These effects relate to } \\
\text { coordination, communication and adaptation to distributed electronic work environments. } \\
\text { Following an analysis of these eCollaboration "effects", a model for distributed project } \\
\text { management is presented. }\end{array}$} \\
\hline \multirow{3}{*}{$\begin{array}{l}\text { Library of Congress } \\
\text { Classification } \\
\text { (LCC) }\end{array}$} & $5001-6182$ & Business \\
\hline & $5201-5982$ & Business Science \\
\hline & HD 30.3 & Communication of Information \\
\hline \multirow{4}{*}{$\begin{array}{l}\text { Journal of Economic } \\
\text { Literature } \\
\text { (JEL) }\end{array}$} & M & Business Administration and Business Economics \\
\hline & M 11 & Production Management \\
\hline & R 4 & Transportation Systems \\
\hline & L 15 & Information \\
\hline \multirow{4}{*}{$\begin{array}{l}\text { European Business Schools } \\
\text { Library Group } \\
\text { (EBSLG) }\end{array}$} & $85 \mathrm{~A}$ & Business General \\
\hline & $260 \mathrm{~K}$ & Logistics \\
\hline & $240 \mathrm{~B}$ & Information Systems Management \\
\hline & $240 \mathrm{~B}$ & Information Systems Management \\
\hline \multicolumn{3}{|c|}{ Gemeenschappelijke Onderwerpsontsluiting (GOO) } \\
\hline \multirow[t]{4}{*}{ Classification GOO } & 85.00 & Bedrijfskunde, Organisatiekunde: algemeen \\
\hline & 85.34 & Logistiek management \\
\hline & 85.20 & Bestuurlijke informatie, informatieverzorging \\
\hline & 85.20 & Bestuurlijke informatie, informatieverzorging \\
\hline \multirow[t]{3}{*}{ Keywords GOO } & \multicolumn{2}{|c|}{ Bedrijfskunde / Bedrijfseconomie } \\
\hline & \multicolumn{2}{|c|}{ Bedrijfsprocessen, logistiek, management informatiesystemen } \\
\hline & \multicolumn{2}{|c|}{ Kennisoverdracht, samenwerking, kennismanagement, virtuele organisatie } \\
\hline Free keywords & \multicolumn{2}{|c|}{$\begin{array}{l}\text { distributed project management, electronic collaboration, episodes, communication, coordination } \\
\text { and adaptation }\end{array}$} \\
\hline
\end{tabular}




\title{
A Grounded Theory Analysis of E-Collaboration Effects for Distributed Project Management
}

\author{
Sajda Qureshi \\ College of Information Science \& Technology \\ University of Nebraska Omaha \\ And \\ Rotterdam School of Management \\ Erasmus University Rotterdam \\ squreshi@mail.unomaha.edu \\ Min Liu \\ College of Information Science \& Technology \\ University of Nebraska Omaha \\ minliu@mail.unomaha.edu \\ Doug Vogel \\ City University of Hong Kong \\ Tat Chee Avenue \\ Hong Kong \\ isdoug@is.cityu.edu.hk
}

\begin{abstract}
The emergence and widespread use of collaborative technologies for distributed project management has brought opened up a myriad of opportunities for business. While the opportunities for off-shore outsourcing and collaborative development are enticing, most tools and techniques for project management focus on on-site, long term relationships and sourcing strategies at a time when inter-organizational relationships are becoming dynamic and temporary. This paper uses grounded theory to analyze data on virtual teams. The analysis uncovers "effects" in the way distributed projects are managed. These effects relate to coordination, communication and adaptation to distributed electronic work environments. Following an analysis of these eCollaboration "effects", a model for distributed project management is presented.
\end{abstract}

\section{Introduction}

Distributed work environments are becoming more attractive as off-shore sourcing and outsourcing strategies are implemented. Some analysts predict spending on distributed project management solutions to grow from \$2 billion in 2002 to $\$ 7$ billion in 2007 (Collaborative Strategies 2004). According to Dave Fowler, vice president of marketing for Groove Networks, the competitive advantage to be gained by outsourcing and offshoring business processes, or just bringing together distributed teams, is too attractive 
to ignore. In addition to offshore outsourcing and sourcing of goods and services, particular benefits of distributed collaboration are being realized as application development and maintenance are being carried out between multiple geographically dispersed organizations. Such innovative working arrangements present decision makers with a number of challenges. In particular, which elements of a distributed project require collaboration? What information, knowledge or expertise needs to be tapped into? Which tools and techniques do employees need to carry out their work in virtual teams? Dave Fowler adds that many companies get bitten by jumping into distributed projects too quickly, without equipping their employees and partners with the proper tools and training to work together virtually (http://www.vrtpri.com/forum/article.php?sid=1856).

The rise of the extended enterprise suggests that the blurring of organizational boundaries is offset by increasingly distinct roles and relationships. Zigurs and Qureshi (2001) suggest that collaborative systems and web technologies have opened up a myriad of possibilities for creating new and different types of relationships, as well as increasing the reach of these relationships. For example, electronic workspaces serve as forums for specialists working on developing new software. Collaborative commerce illustrates these developments well. It has been associated with the need for organizations to work together in planning, sourcing and the execution of goods and services. Distributed project management requires collaboration between organizations for 1 ) the sourcing of resources and matching right partners to needed capabilities, 2) planning resource requirements for future demand and 3 ) execution of projects by mobilizing appropriate, dispersed resources to develop or deliver products and to provide services.

In view of these trends, Scott Kownlar (2004) suggests that "E-business as a concept is being redefined to include not just transaction making, but other collaborative activities that leverage the Web as well". There is a sense that as people and organizations do business with each other over the web, the need for collaborative technologies, processes and structures will be come necessary (Kownlar 2004). Distributed virtual projects are making an impact in supporting both formal and informal temporary alliances between organizations and groups. This provides organizations with the flexibility they need to meet changing customer needs and expectations. However, 
current approaches to project management focus on command and control of distributed processes and not on facilitating distributed work.

At the same time research in virtual teamwork has provided a wealth of insight into the ways in which virtual teams work. This concept has been developed through many years of research in how people use various collaborative technologies to achieve their tasks and objectives (refer to Qureshi and Vogel (2001) and Powell et al (2004) for a review of this literature). It appears that the use of collaborative technologies to support organizational processes has the potential to increase productivity in organizations (Lipnack and Stamps 1997, Robey et al 2000, Nunamaker et al 1989). Research carried out by Koch (2001) suggests that processes such as the compensatory adaptation to lean media brings about a "positive" effect on the quality of outcomes. Qureshi and Vogel (2000) suggest that virtual teams go through processes of technological, work and social adaptation to their new work environments. In their study of multiple geographically and temporally dispersed teams, Rutkowski et al (2002) draw special attention to the structure of electronic communication required to support efficient virtual teaming. It appears that a complex set of social factors govern collaborative technology use in organizations. Some even suggest that collaborative technologies such as email actually increase hierarchy in organizations (Perin 1991, Qureshi 1998).

It appears that the use of collaboration technologies is essential for supporting distributed projects. Electronic collaboration is the use of networking and collaborative technologies to support groups in the creation of shared understanding. eCollaboration fosters new kinds of collective work made possible with advanced collaboration technologies. The use of collaboration technologies enable conversations with new kinds of properties- these shift from being fixed to being externalized and negotiated (Schrage 1990 p.102). This paper draws upon research conducted in virtual teams and conducts empirical research to investigate the question: What are the key factors affecting success in distributed projects? Following an analysis of interaction on distributed virtual teams this paper concludes with electronic collaboration effects that determine the success of distributed projects. 


\section{Theoretical Background}

\section{Issues for managing Distributed projects}

Virtual enterprises are composed of many different, dynamic and temporary distributed business processes in different, widely dispersed areas or countries. Communication is often seen as the most important factor contributing to the success of individuals, project teams, and organizational growth. Effective communication is vital for virtual teams that cannot meet in face-to-face settings (Baker 2002). One challenge for managing communication among distributed processes is that advanced technology is needed to offer an environment that provides reliable and timely task-related information sharing and a support for rapid decision-making. Baker's (2002) study found that for virtual teams, the addition of video to audio-based communication can result in improved decision making when compared to other collaborative technologies. Another challenge is coordination. As the business processes are performed by various enterprises, the management of the value-chain is a complex task, especially when some degrees of coordination are envisaged for support (Pereira Klen et al, 2000).

\section{Outsourcing Challenges}

The trend towards outsourcing of information systems since the late 1980s presents many challenges for management. Companies outsource projects to external or international business enterprises, but they still have to manage the process. Ho (2003)'s research found that the presence of strong ties between manager and contractor and the lack of prior outsourcing experience increased the persistence of managerial expectation. In turn, persistence of expectations had a distinct influence on managerial perceptions of contractor performance. The formal coordination of performance in organizations is accomplished through the managerial process. Both supervisor and subordinate must have shared understanding of performance expectations (Watson et al, 1998). The trend of outsourcing is developed as a consequence of a new strategy of conducting business, which is the concept of virtual enterprises (Pereira, Klen et al., 2001).

In their study of communication and coordination in the virtual office, Watson et al (1998) found that telecommuters were significantly more satisfied with office communication than were non-telecommuters. They found that in virtual work arrangements, authority, power, and role definitions, as well as interpersonal attraction and compatibility are 
constructed through social interactions among group members. The formal coordination of performance in organizations is accomplished through the managerial process. Both supervisor and subordinate must have shared understanding of performance expectations. Employees develop relationships and coordinate work activities through encounters and informal discussion.

Research shows that firms prefer to outsource facing competition with scale economies (i.e., the cost per unit of demand is decreasing in demand) even if the companies they outsource to do not have better technology than the firms' technology (Cachon and Harker, 2002). Because scale economies make price competition brutal, firms can benefit from outsourcing to mitigate price competition. Most companies choose outsourcing because it can reduce cost and improve performance, but there could be hidden cost that managers couldn't pinpoint or aren't aware of. These hidden cost could lead to deemed failure (Barthélemy, 2001). As outsourcing increases, the need for understanding better relationships between parties, management of distributed vendors and identifying hidden cost become more critical.

For distributed project management due to outsourcing, it is important to define the relationship among the participants. Kern (2002) uses interaction approach to study the relationship in information technology outsourcing and found that both formal and informal information exchange pervade all interactions. Information exchanges in fact define a key operational effectiveness measure in outsourcing relationships (Kern and Willcocks, 2002). To ensure good communication is not an easy process, it often requires thorough planning of an appropriate communication structure.

\section{Virtual Project Teams}

Virtual teams rely on computer-mediated technology to share and communicate information. It is very important for geographically dispersed members to have mutual knowledge for effective communication. Virtual teams can be described as groups of workers who are geographically, organizationally and/or time dispersed work together to using information technologies to accomplish one or more organizational tasks (Jarvenpaa \& Leidner 1999, Powell et al. 2004). In today's global world, members of a virtual team usually work and live in different countries and are culturally diverse. This kind of global virtual team almost solely relies on computer-mediated technology to 
share and communicate information. Virtual teams are usually assembled as business needs emerge and disassembled when the organizational task finishes. Although they are short lived, their performance impact on the organization is profound. While virtual teams offer a wide range of potential benefits to organizations, implementation will be at risk if organizations fail to adequately address the many challenges present in the virtual context (Powell et al. 2004).

The critical factors affecting virtual teams development include the team characteristics (e. g. size, geographic dispersion and members shared work experience) and task characteristics (e.g. complexity, uncertainty, ambiguity and difficulty), information and communication technology choice, project management strategies, communication patterns and information sharing and processing (Paré and Dubé, 1999). These factors interplay with each other and their inter-relationship are potentially relevant to the functioning and effectiveness of virtual teams. Studies using collaborative technologies have studied variables such as problem solutions generated, number of options and ideas generated, and satisfaction with the outcome were used in experimental (Connolly et al., 1990; Nunamaker et al., 1991; DeSanctis and Gallupe, 1987) and field studies (Nunamaker et al., 1991).These studies measure the effect of process support factors such as anonymity, group memory, parallel communication and certain media effects in computer support for structuring face-to-face group processes.

To the extent that this research assumes that the objective of successful meetings is to improve communication, generate as many alternative solutions to a problem as possible, and to separate the personalities of the participants from the problem, its success is restricted to situations in which these assumptions hold. For globally distributed projects, that need to successfully manage outsourcing contracts (Ho, Ang and Straub, 2003) or manage risks, relationships and performance issues inherent in the extensive use of external service providers and business allies (Willcocks and Plant, 2003) a more interpretive approach is required. Such as study should bring out the key factors effecting the success of virtual project teams. Similar to Orlikowski et al's (1995) study of how computer conferencing was incorporated into the R\&D division and identified types of mediating activities that members performed in this process. The following section develops a methodology to identify the electronic collaboration effects that mediate success in distributed projects. 


\section{Research Methodology}

This research follows a grounded theory approach that entails the discovery of theory from data systematically gathered and analyzed from the research process (Glaser and Strauss 1967, Strauss and Corbin 1998). Theory generated from data can usually not be completely refuted by more data or replaced by an alternate theory. Within this approach, theory is discovered first, through conceptual categories and their conceptual properties; and second, through hypotheses or generalized relations among the categories and their properties (Glaser and Strauss 1967). Theory can be further refined through a process of disciplined imagination or "sensemaking" (Weick 2001). This is a process of collective sense-making about what people have been doing, what they might want to din the future, including how they might want to do it (Harmon, 1990).

Data was collected on 21 distributed virtual teams comprising of students from Erasmus University in the Netherlands and from the City University in Hong Kong. The students worked together using eRoom $^{\mathrm{TM}}$ software which provided file sharing, discussion, voting and chat tools. A particular feature of this software was that it provides each virtual team with its own "room" or folder equipped with these features. The data was collected over a period of three months in 2000. This sample was selected from a series of similar team interactions from 1999-2001 as it provided the most virtual interactions related to distributed project management. Data was gathered through observations and transcripts of electronic collaboration and was coded using Strauss and Corbin's (1998) open coding method. Conceptual categories and their properties were identified in the transcripts of electronic collaboration. Theoretical sampling was used to group coded episodes into these categories. Using the open coding technique, data are broken down into discrete parts, closely examined and compared for similarities and differences. Events, happenings, actions and interactions that were found to be conceptually similar in nature or related in meaning were grouped under more abstract concepts. The results of the open coding and conceptual category formation are reported and analyzed in the following section.

\section{Results and Analysis}

Three main categories emerged from the open coding. These related to communication, coordination and adaptation in virtual teams. Episodes of communication, coordinaition and adaptation represented the effects of collaborating electronically on a virtual team. 
These episodes emerged from the coding of the electronic transcripts and illustrate the three categories.

\subsection{Communication}

Communication was found to play a central role in virtual team performance. Effective communication means not only passing the information to the receiver but also understanding and utilizing the information passed. Teams operating in the virtual environment face greater obstacles to orderly and efficiently information exchange because they rely heavily on information technology to communicate (Powell et al, 2004). The results of the coding suggest that there were numerous issues with communicating electronically. Episodes relating to communication were both positive and negative. The consequences of these episodes affected the extent to which the virtual team was successful. Table 1, summarizes the number of episodes concepts relating to experiences with electronic communication and their consequences.

\section{Table 1: Number of Communication Episodes}

\begin{tabular}{|l|l|l|l|}
\hline Categories & $\mathbf{F ( x )}$ & Outcome & $\mathbf{F}(\mathbf{y})$ \\
\hline Positive eCommunication & 12 & Shared understanding & 11 \\
\hline Issues with eCommunication & 8 & Effective collaboration & 4 \\
\hline Total & $\mathbf{2 0}$ & & $\mathbf{1 5}$ \\
\hline
\end{tabular}

\section{Positive eCommunication}

Sixty percent of the episodes relating to communication were positive (16 out of 20 see Table 1). The following episode suggests that the virtual team actually experienced more open communication:

For me personally it was a better environment for open communication. I had the opportunity to think first thoroughly about my discussion points and then put it up on the eRoom.

Different points of view and sources of knowledge generate tremendous results when combined.

Working with an multi-cultural team in an virtual environment makes disappear all the differences between different cultures. 
The result of the positive communication experiences meant that members of the group were able to communicate the different perceptions to each other. This brought about shared understanding.

\section{Shared Understanding}

The process of creating shared understanding is the communication of different perspectives and exchange of information through which behaviors are modified and/or action is carried out. In this investigation shared understanding was developed through asynchronous documented communication that was structured and formal. Shared understanding was recorded in 11 of the 15 episodes pertaining to the consequences of positive electronic communication. The following episodes illustrate the creation of shared understanding by the exchange of experiences, knowledge and ideas.

Students from different countries are facing different contexts, so more comprehensive decisions can be reached. Some points may be quite localized which are not common in my country. More ideas are found.

We think it was an interesting experience to work in a virtual team. Besides the good things that came from joining the project (sharing knowledge, work together with people from different cultures) there are several problems with virtual communication. It was a very short period, so it was difficult to create a good communication protocol. The discussion wasn't very intensive under time restrictions. Over all it was a nice experience.

It was a nice experience. But it seemed we were talking to each other not w/ each other. (There was not really a "listening" process, "listening to one anothers' comments)

From the transcripts of the episodes that illustrate the creation of shared understanding, it appears that certain key outcomes effected positive electronic communication. These outcomes were more comprehensive and informed decision making, more ideas generated and increased performance under time pressure. 


\section{Negative eCommunication}

Of the total number of episodes relating to communication (20), only eight episodes suggested that there were issues with communicating electronically (see Table 2). The following two quotes illustrate episodes in which there were problems with communicating electronically:

In order to communicate effectively, more explanation and clarification are needed.

In potential it [the collaboration technology] leads to a better discussion, but because of cultural and practical differences and constraints this potential is not fully exploited.

The eight episodes related more to problems with interpersonal communication rather than issues with the technology. These issues with communicating electronically negatively impacted the success of the project. In particular, the effectiveness with which the group was able to perform was compromised.

\section{Collaboration Effectiveness}

In order to be effective, a virtual team needs to enable projects to be carried out and managed. Only 4 out of the 15 episodes pertaining to the consequences of negative electronic communication pertained to effectiveness. According to the transcripts of the episodes pertaining to effectiveness, communication across time zones and limitations of the technology compromised the effectiveness of communication.

The issues that we came up with, in cooperation with the students from Hong Kong, were listed in the workspace. So we could easily pick up the discussion at any moment. This is very different in a face to face discussion.

I think this tool provides a very effective way for discussions: in a face2face discussion you want to say what you think and the others should shut up. With this tool, you are curious to see what the other party has replied to your comments. 
Communicating on virtual teams is important for distributed project management as knowledge becomes more specialized and fragmented, so does the need for knowledge sharing between individuals holding different types of expertise. Knowledge sharing is especially important in virtual teams because it can affect the success of the distributed project. Because shared understanding and effective collaboration are outcomes of successful communication in virtual teams, it needs to be supported through collaborative processes and technology.

\subsection{Coordination}

Global dispersion complicates the coordination of collective action in several ways. First, it implies physical distance and a shift towards remote communications (Evaristo \& Fenema, 1999). Second, people joining from different sites bring their unique sociocultural background, thus adding to the diversity of globalized collective action (Krauss \& Fussell, 1990). And third, time zone differences disrupt interaction flows across sites. Over recent years, a mixed picture has been sketched on this third factor. On the one hand, people have claimed that time differences stretch working days. Their work could 'follow the sun'. This suggests that sites can pass on intermediate deliverables or questions at the end of a working day to a site west from theirs where a new day has just begun (Carmel \& Zettl-Schaffer, 1997). A sequential relay race would spin the globe and never stop until the work is finished. On the other hand, time zones delay work accomplishment (Knoll \& Jarvenpaa, 1998; Meadows, 1996b).

People miss real-time phone conversations and chats that would solve problems in a short time frame. Instead, they have to shift towards a more asynchronous communication pattern that lengthens problem-solving cycles. Of the total number of episodes relating to coordination, most episodes were related to group collaboration and involvement in the project where time zone differences were a key barrier to be overcome. A problematic outcome of the time zone differences was delays in response and waiting. Productivity and learning were found to be outcomes of group collaboration and involvement. These effects are illustrated in the following Table 2. 
Table 2: Number of Coordination Episodes

\begin{tabular}{|l|l|l|l|}
\hline Categories & $\mathbf{F ( x )}$ & Outcome & $\mathbf{F}(\mathbf{y})$ \\
\hline Time zone difference & 7 & Response delay/waiting & 16 \\
\hline Group Collaboration & 13 & Productivity & 6 \\
\hline Involvement & 16 & Learning & 9 \\
\hline Total & $\mathbf{3 6}$ & & $\mathbf{3 1}$ \\
\hline
\end{tabular}

\section{Time zone difference}

The time zone difference between the Netherlands and Hong Kong is 7 hours. This meant that most coordination of tasks took place asynchronously. Only 7 out of a total of 36 episodes related to time zone differences. It appears in this distributed setting, that time zone differences were a challenge but one that could not be over come. The following episodes suggest that the delays were only a part of the issues that the time zone differences brought about.

Our tasks do not restricted by time and place. It actually saves lot of time and money for a global team to work in a virtual environment. But if any one of the members want to be a free rider, much time is spent on waiting and the work will be very ineffective.

This task gave us the opportunity to get familiar with working in a virtual community. However, as the Chinese members are not familiar with us and are in a different time zone, this causes some communication and coordination problems.

A clear outcome of the time zone differences was the delays in obtaining responses from group members and the waiting.

\section{Response Delay/Waiting}

Success in distributed projects requires interactions among different members. The time zone differences brought about delays and increased the waiting time need to carry out a task. 16 out of a total of 31 episodes relating to outcome effects of electronic collaboration related to the ways in which participants dealt with the delays in responses and waiting for feedback from their team members seven time zones away. 
Very often, we spend much time on waiting feedback. I don't know what the other members are doing. It should be better if video equipment is applied.

The only difficult feeling I have working in virtual environment is that you would expect to wait for response from your team with great patience.

Such episodes of relating to waiting for feedback and delays in meeting deadlines suggest that there was not much apart from waiting that group members could do. Key hand off points and division of tasks had to be coordinated in the light of such delays.

\section{Group Collaboration}

Collaboration is the act of constructing relevant meanings that are shared by all parties involved to achieve congruent goals. The act of collaboration in groups is the act of shared creation and/or discovery in which two or more individuals with complementary skills interact to create shared understanding that none had previously possessed or could have come to on their own (Schrage 1990 p.40). The results of this research indicate that 13 out of 36 episodes related to this effect of electronic collaboration. Group collaboration took place for all three states of the project: planning, sourcing and execution.

Coordination between all team members is essential. When working with team members using an application such as eroom you have to consider planning etc. in advance to get all aspects clear so everyone can work toward an integrated answer.

All members contribute to the project. We can share our ideas.

It is difficult to work as a Dutch student group on such a task. It is easier to work individually with a group of students in an virtual community. Then you do not have to tune off focus separately with your Dutch group.

The episodes suggest that the group collaboration was a key effect in enabling the project to be a success. The records suggest that the outcome of group collaboration was productivity. 


\section{Productivity}

Group collaboration impacts the productivity of a group by influencing the parts of the project that have been worked on.

That it is (in theory) possible to get on ongoing process of productivity: one part of the team can work when the other part of the team is asleep: productivity advantage is in our view the result. When successfully applied by a company it can provide a competitive advantage vis a vis competitors who do not use this

It's difficult to coordinate the work with a group member in another country with a different time-zone. The coordination between the group members in Rotterdam is much easier. Direct interaction (at the same time) is better than reacting on a subject the other day, because it is easier to discuss the theory in depth.

Coordination between all team members is essential. When working with team members using an application such as eroom you have to consider planning etc. in advance to get all aspects clear so everyone can work toward an integrated answer.

The episodes suggest that ways in which group collaboration enabled productivity to be achieved was: by enabling the project to be worked on throughout the 24 hour cycle, and planning ahead. However productivity was compromised when some groups were not able to coordinate their interaction across times zones.

\section{Involvement}

This effect of electronic collaboration on the success of distributed projects had the most episodes relating to coordination: 16 out of a 36 . Involvement in a distributed project is the ability to participate or interact in a virtual team setting. This requires an awareness of the group and ability to engage in its efforts. The following episodes provide examples of involvement in virtual teams:

The team worked very hard to succeed the mission. Mission was completed successfully, thanks to the support of all team members and our gabber in HK. We look forward to keep on working via this program/application. 
It's difficult to get the overseas party involved in getting the task done.

Because there were no specific rules about the interactive discussion it was not possible to work like that.

The interaction is slower than F2F or teleconferencing and sometimes it is difficult to focus on the issue.

These episodes suggest that achieving involvement was not trivial. Interactions were slower, there were no rules of engagement and a lack of awareness of the overseas participants. Despite these challenges, some participants worked hard to achieve involvement and successful engagement in their team.

\section{Learning}

When members of a group are able to involve themselves in a joint project, they are able to exchange ideas, information and build upon each others' ideas. This brings about learning - this is an essential ingredient for projects that are to produce customized products or services. The following episodes illustrate some of the learning effects of electronic collaboration:

Team Learning is important.

Apply the theory in the articles in practice was very useful. It becomes more clear what is meant by remarks in the text. You learn theory when 'playing' with it in the 'real world'. A useful addition to the articles we believe.

We learn to discuss a topic with somebody with different background and in different geographical area.

Everybody's input is equally important.

These episodes suggest that the experience of learning took place theoretical knowledge was exchanged, discussed and applied to produce a report. Learning is 
outcome of involvement as long as there is a sense that the contributions are taken into account and brought together. Coordinating involvement to bring about learning requires the use of collaborative technologies at a new level. Schrage (1990) adds that collaborative technologies have changed the contexts of interaction completely. Many conversations can take place at the same time. Ideas generated by different people on a shared screen for all to see inspire conversations within the group. Ideas are both external and manipulatable. People can create icons to represent ideas and concepts that others can modify or manipulate until they become both community property and a visual part of the conversation.

\subsection{Adaptation}

Adaptation is the process by which members of a group learn to engage with themselves, the distributed work environment and the collaborative technologies with which they work. Virtual teams need to adapt their practices constantly to the organizational challenges in three aspects: social, technology and work adaptation. Virtual teams members need to change their own way of doing things to adapt to the virtual environment. It affects the work process itself and the way in which work is carried out (Qureshi and Vogel, 2001). This process was encountered frequently in the virtual team episodes and effected the extent to which the virtual teams were able to successful complete their projects. Of the three forms of adaptation encountered, technological adaptation was most apparent - it occurred 44 out of a total of 56 episodes. Yet no outcome could be identified for technological adaptation. The outcome of social adaptation was found to be conflict resolution and the outcome of work adaptation was found to be lateral thinking. The electronic collaboration effects for adaptation are illustrated in table 3:

\section{Table 3: Number of Adaptation Episodes}

\begin{tabular}{|l|l|l|l|}
\hline Categories & $\mathbf{F}(\mathbf{x})$ & Outcome & $\mathbf{F}(\mathbf{y})$ \\
\hline Social & 4 & Conflict resolution & 5 \\
\hline Work & 15 & Lateral thinking & 12 \\
\hline Technological & 44 & & \\
\hline Total & $\mathbf{5 8}$ & & $\mathbf{1 7}$ \\
\hline
\end{tabular}




\section{Social}

Social adaptation requires team members to conform to the created patterns of interaction, established rules and knowledge. A key issue to effective social adaptation is what sort of communication etiquette and norms of behavior evolve on the electronic social space and which of these is most conducive to the creation of technologysupported learning environments. Only 4 episodes out of a total of 58 were dedicated to social adaptation. Examples of such episodes are illustrated below:

When I'm in a group participating in a project or working on a case, we make always some time for a little social, informal communication to get to know each team member a little better. Most of the time I did this by drinking a beer (or something else) with the whole group and talking about hobby's, the weather, the things that student find interesting. All this is very difficult to do, when one of your group members lives on the other side of the world. You may decide to go a chat- or gaming zone and do your social communication over there, but I don't think this is the same.

It is easier to communicate, discuss and explain face-to-face then online discussion. Also because of the language boundary it is difficult to explain what you really mean in an online discussion. But it is a good tool, when it is necessary to work with people around the world to get a task done.

It appears from the few episodes that social adaptation was very difficult to achieve on the virtual teams. When it did take place, language and geographical boundaries made it very difficult to sustain social adaptation.

\section{Conflict resolution}

In the event that social adaptation did take place, a clear outcome was the resolution of conflict. There were only 5 episodes in which some sort of conflict resolution or suppression took place.

My group members seldom comments on my points. Rather they added their own points. I think some comments share among each other are more helpful instead of just giving ones own points. 
This and other episodes suggest that much of the conflict was latent and covert. Very little flaming was encountered.

\section{Work}

Work adaptation occurs when people adapt the technology to their own ways of working. When groups are involved in changing organizational norms and values while using the collaborative technology, the process of work adaptation takes place. Only 5 out of the 17 episodes were related to work adaptation. Examples are illustrated below:

I think that in the discussion with the students from Hong Kong, e-room provides good opportunities for open discussion. An essential aspect however is the fact that the discussion members are not in the same place. Face-to-face conversations may have been a better solution if all persons were in the same place.

Another factor that contributes to the success of using a group support system is the number of people using it. It has no effect when two people use a system like e-room, but in our case it was more appropriate to use a group support system because of the large size of groups.

We found out that some cultural differences were very disturbing, because some messages made a wrong impression while we didn't mean it that way. But this is a good experience for all of us because this made us realize that you have to keep that in mind while doing business with people of other cultural backgrounds.

These episodes suggest that work adaptation is an essential electronic collaboration effect in that it enables virtual teams to overcome cultural differences, provides opportunities for open discussion and enables large geographically dispersed groups to work together. An outcome of this form of collaborative work is that team members had to find solutions to unconventional ways of working and problems. This forced lateral thinking and use of different perspectives in developing their final product. 


\section{Lateral thinking}

Lateral thinking is the use and implementation of new and unconventional forms ideas to solve problems and or carry out tasks. This was an outcome of work adaptation. 12 of the 17 episodes on outcomes of electronic effects concerned lateral thinking. Examples of the use of lateral thinking in distributed projects are given below:

As members come from different contexts, thinking from different perspectives comes out.

Feedback on your contribution is very useful: You quickly know what other members/ people think of your remark and other viewpoints are introduced which can indeed work clarifying. Other people can steer you into new thought areas which are interesting.

Episodes of lateral thinking involved creativity in the way in which the projects were carried out as well as the content of the project reports. The lateral thinking episodes suggest that different viewpoints were taken into the preparation of unexpected answers to routine questions.

\section{Technology}

Technology Adaptation occurs when people learn how to use the technological tools available to achieve their communication goals. It involves single-loop learning, in which group members adjust their procedures according to changes in the environment. The more flexible the technology, the more easy the team members will adapt to. The results of this research indicate that 44 out of 58 episodes related to technological adaptation. Most of these indicated frustrations with the technology and additional features that were needed. Examples of such episodes are given below:

It [the technology] provides a good communication area to discuss, comment and finalize the small group projects. Moreover, voting function helps us to find the most important ideas/opinions.

The eRoom provides good communication channels. You can create folders for placing documents. Further, you can create some topics to start a discussion 
with other groups. Only when you start getting familiar with this site, it's a little bit difficult finding your way through the pages.

The speed of the system should be increase to faster the processing. And the Eroom should be updated immediate without kicking any keys.

Yet, the interface of the program could be better. We had problems moving files from one folder to the other.

We think e-Room is not so an effective communication tool at all. Arguments:

- the user interface is rather confusing, you cannot personalize e.g. HKNTH14 into a more suitable name

-you have to explore every topic to see what's new. There should be some popup window to show you what are new contribution when you just logged in -every stage of the project should have a time path included so e-Room can monitor the advances of you project (because of the different time zone communication is rather difficult, i.e. time consuming)

From the episodes it is clear that the technology presented many challenges. Adapting to the technology was difficult because of the design features or lack of. There was little support for organizing communication and coordination of the distributed work. The lack of immediacy in distributed communication was aggravated by the absence of notification functions indicating new input to the "rooms" or the entrance or exit of members from the rooms.

\section{Model of Distributed Project Management}

The results of this research have uncovered electronic collaboration effects and their outcomes. The extent to which these effects influence the success of distributed projects and provide guidance for managing distributed projects is the subject to this and the following sections. A model of distributed project management is developed here to provide practical insight into the electronic collaboration effects and how they may be used to manage distributed projects. In particular, insight from this model can be used to manage projects across different organizations. Information and communication technology connects manufacturers, suppliers, customers, competitors and 
complementors to form a value network. A company in a value network can concentrates on the functions that it does best and rely on other partners to carry out the other functions (as cited in Willcocks and Plant, 2003). But for this value network to create value in its real sense, it requires cooperative attitudes, clear understanding of central objectives, electronic coordination and communication, adaptations and flexible modules, cultures and workforces (Willcocks and Plant, 2003).

The analysis of this research has shown that positive communication can bring about shared understanding and effective collaboration. Members in a distributed project management environments often have expertise in a specific area, so there is a great need for knowledge sharing via effective communication. The lack of mutual knowledge and shared language among team members can hamper communication. Failure to establish mutual knowledge can result in poor decision quality and productivity, failures of information exchange and interpretation, amplify the problems and negative consequences of attribution (Cramton, 2001). Frequent and effective communication can solve coordination difficulties and help make the adaptation process smooth. These effects and their relationship to each other are illustrated in the following Model of Electronic Collaboration Effects in Figure 1 below:

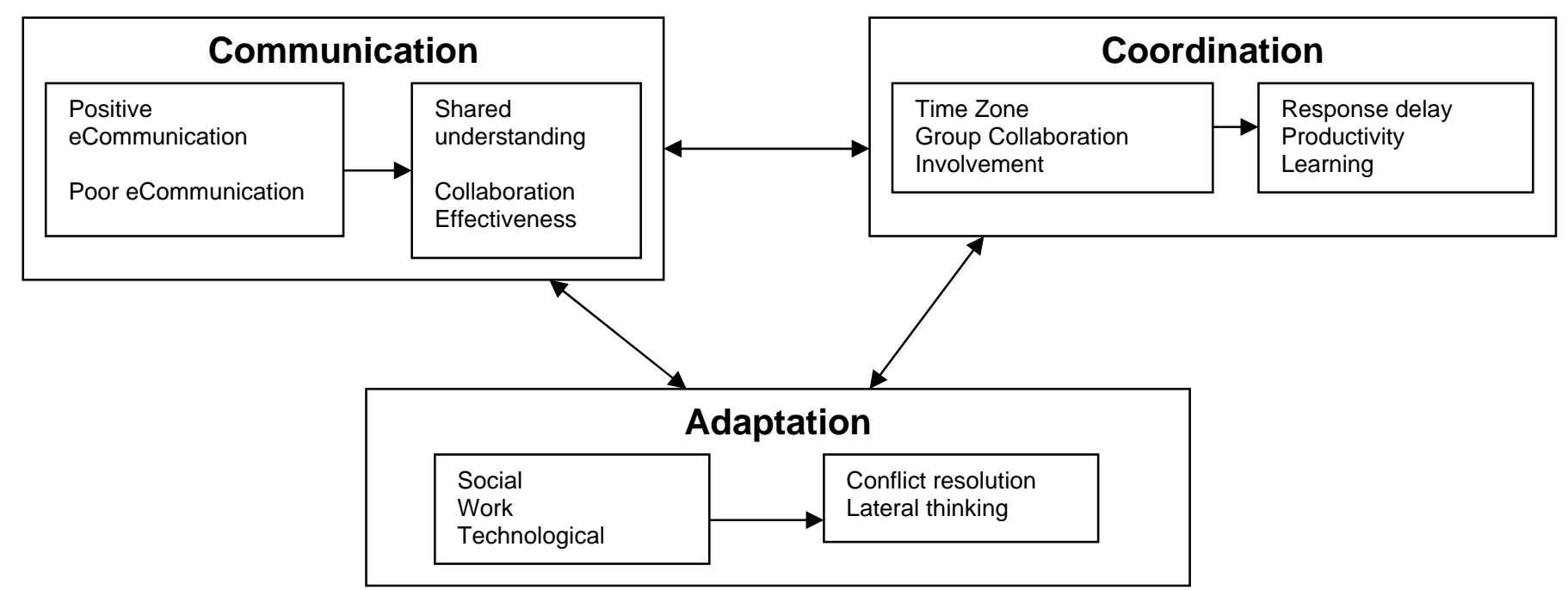

Figure 1: Model of E-Collaboration Effects

This model suggests that exchanging information on each project member's schedule will help to coordinate the team. Sharing project schedules and task related information can help members to overcome their respective adaptation difficulties and enable conflicts to be resolved more easily. Distributed project management requires a high 
degree of communication and coordination. Distributed project decisions refer to the degree to which control over resources necessary to complete a project, such as software, hardware and data, are distributed among project participants (Tractinsky and Jarvenpaa, 1995).

Distributed project teams socialize to adapt to new global and distributed environments. Changes in work environments can be managed to increase the satisfaction with communication in virtual environment. Communication decisions and information processing capabilities are major challenges to global organizations and are one of the most important factors that dominate distribution decisions in global projects. Through communication process, social structures can be produced, reproduced and changed (Sarker and Sahay, 2003). Tractinsky and Jarvenpaa (1995)'s study suggest that global project management emphasizes more local units' responsiveness and the need for continuous, uninterrupted 24-hour services. Well-managed coordination process that follow mutually-agreed procedures and rules can encourage constructive communication and create a feeling of "closeness" despite of the cultural, social and working differences.

\section{Implications for Research and Practice}

This section focuses on implications for research and practice with respect to communication, coordination and adaptation. Space constraints require brevity. As such, the issues and examples presented should be seen as the "tip of the iceberg." In virtual teams, effective use of communication technology has a profound influence on the communication, coordination and adaptation processes. The above model illustrates the interrelationships between these three processes and suggests how the eCollaboration effects can be used to drive the three processes. Based on insights depicted in the above model, this section provides implications for research and practice that serve as guidelines to enable successful distributed projects to be managed.

\section{Communication}

Clearly, communication plays a major role in virtual teams and, consequently, distributed project management. Under circumstances of multiple cultures and lack of a common language, consistent communication becomes even more important, especially given distributed constraints, e.g., general inability to meet face to face or even at the same time. A noted success factor in virtual teams has been sustained communication in pursuit of shared understanding. Implications for research and practice are many. 
Trust is especially elusive and can be fleeting in virtual teams especially when communications are sparse and cultural differences are large. Trust can be envisioned as a moderator in virtual interactions that can render intervention and engagement efforts to be more (or less) useful (Lee et al., 2003). In this sense trust does not directly impact team results but serves to strengthen or weaken the impact of attempts by internal or external stakeholders. Lack of trust tends to discourage communication amongst team members.

Given the importance of communication in virtual teams, it is essential to provide side channels through which virtual team participants can engage in interactions other than direct task focus. Although historically seen as "noise" by some researchers and businesses, these non-task focused interactions play an important role in achieving team member trust and sustaining communication and involvement of distributed team members. In the absence of side channels and discouragement for non-task related communication in the context of focus on content and deliverables, disruption of project momentum and easily occur. Exactly how all of this is managed in distributed teams remains an important research issue.

\section{Coordination}

Coordination is a constant challenge in distributed teams and management becomes a central issue. Tried and true practices in traditional contexts are not necessarily as potent in distributed circumstances, especially in multi-cultural considerations. The challenges are many but, also, opportunities exist as multiple perspectives and roundthe-clock work advantages emerge. Here, again, implications for research and practice are many. However aspects of leadership and time visions are particularly salient.

Leadership in virtual teams varies widely as a function of circumstances and culture. However, a rotating style of leadership is especially popular. As such, leadership is based on characteristics of the task at hand and the fit of a particular team member with that task. There are also a number of supportive roles in virtual teams that bear mention. For example, there is a "shepard" role in that a team member may consciously keep team members in touch with each other through messages that have no task- 
relevant content. The overall objective is to make sure team members recognize the existence and social sensitivity of the team.

There are time vision differences in addition to time zone differences (Saunders, et al., 2004). In this sense, concepts of "saving time" or "losing time" may be completely at odds with perspectives from other parts of the world in which time may be seen as harmonic and cyclical in nature. Time visions must be recognized and managed in order for the full potential of virtual teams to be realized. The combination of time visions and multiple time zones can be used powerfully in the context of distributed project management or can become a nightmare if under-appreciated. Research has only begun to tap the issues and presents tremendous opportunities for contribution to knowledge.

\section{Adaptation}

Adaptation is essential for distributed project management and presents many challenges as well as opportunities. Sensitivity to the need for change and its timing can dictate project success of failure. Conforming to agreed upon norms and conflict resolution are paramount. Work adaptation is confounded by differences in culture and perspective but this also provides a catalyst to lateral thinking that can provide crucial input in creative problem solving. As noted, technology plays a key role in adaptation.

The choice of which technology to use for a particular task or activity can vary as a function of cultural characteristics. For example, a local team with a propensity to carefully considering issues before engaging remote team members may well prefer an asynchronous technology rather than a synchronous technology. Under these, circumstances, a move by remote team members to "clarify situations" through a video conference or online chat may be met by considerable resistance. The careful choice of technology and its flexible and thoughtful use is a key contributor to distributed project success that is only beginning to be understood and warrants considerable extended research.

It is often difficult to surface issues and sustain productivity in virtual teams unless an environment is created in which motivational, contextual, and structural barriers have been addressed and overcome (Rutkowski, et al., 2002). An accumulation of barriers 
may easily prohibit synergistic interaction and slow team progress to the point that creative content generation is seriously impaired. Here again, technology plays as crucial role in supporting distributed project management. Technology can assist in lowering barriers and providing additional degrees of freedom to address circumstances. However, considerable research is necessary to fully appreciate these implications and provide insight that can guide practice.

\section{Summary and Conclusions}

This paper has uncovered the electronic collaboration effects that influence the success of distributed projects. Following the development of a theoretical background in which the challenges facing distributed project management and outsourcing are discussed, a grounded theory approach is developed to address the key questions. Data on virtual team projects is analyzed using open coding and categories are formed. An analysis of these categories reveals electronic collaboration effects and outcomes. The insights from these effects are highlighted using episodes and used to develop a model of distributed project management. The key contribution of this paper is in the uncovering and analysis of the electronic collaboration effects using a grounded theory approach. A model has been built to help understand the relationship between those different "effects". Further research to test this model in the field should be carried out as the influence of the eCollaboration effects may vary according to the nature and function of the distributed project. Many opportunities remain for continued research as we explore the complexities of these effects and their extended implications. 


\section{References}

Baker, G. "The Effects of Synchronous Collaborative Technologies on Decision Making: A Study of Virtual Teams", Information Resources Management Journal, 15(4), 79-93. 2002.

Barthélemy, J. "The Hidden Costs of IT Outsourcing", MIT Sloan Management Review, 42(3), 60-69. 2001.

Cachon, P. Gérard and Harker, T. Patrick. "Competition and Outsourcing with Scale Economics", Management Science, 48(10), 1314-1333. 2002.

Carmel, E., \& Zettl-Schaffer, K. Globally Dispersed Software Development Teams: A Definition and Framework. Paper presented at the International Conference on Management of Technology. 1997.

Collaborative Strategies. Distributed Project Management: A Marketplace and Software Vendor Analysis, 2004.

Connolly, T., L.M. Jessup and Valacich, J.S. "Effects of Anonymity and Evaluative Tone on Idea Generation in Computer-Mediated Groups." Management Science. 36(6), 689-703. 1990.

Cramton, D. C. "The Mutual Knowledge Problem and Is Consequences for Dispersed Collaboration", Organizaitonal Science, 12(3), 346-371. 2001.

Evaristo, R., \& van Fenema, P. C. “ A Typology of Project Management: Emergence and Evolution of New Forms". International Journal of Project Management, 17(5), 275-281. 1999.

Glaser, B.G. and A.L. Strauss, The Discovery of Grounded Theory: Strategies for Qualitative Research. Aldine de Gruyter:New York. 1967.

Harmon, M. M., “Applied Phenomenology and Organization", PAQ, pp10-17. 1990.

Ho, T. V., Ang, S., and D. Straub. "When Subordinates Become IT contractors: Persistent Managerial Expectations in IT Outsourcing", Information Systems Research, 14(1), 66-86. 2003.

Jarvenpaa, S. and Leidner, D. "Communication and Trust in Global Virtual Teams," Organizational Science, 10(6), 791-815. 1999.

Kern, T and Willcocks, L. "Exploring relationships in information technology outsourcing: the interaction approach", European Journal of Information Systems, 11, 3-19. 2002.

Knoll, K., \& Jarvenpaa, S. L. Working Together in Global Virtual Teams. In M. Igbaria \& M. Tan (Eds.), The Virtual Workplace (pp. 2-23). Hershey, USA: IDEA Group. 1998.

Kownslar S. "Collaborative Commerce." ACM Ubiquity. Retrieved February 232004. http://www.acm.org/ubiquity/views/s_kownslar_1.html

Kock, N. "Compensatory Adaptation to a Lean Medium: An Action Research Investigation of Electronic Communication in Process Improvement Groups." 
IEEE Transactions on Professional Communication. New York: 44(4). 267-285. 2001.

Krauss, R. M., \& Fussell, S. R. Mutual knowledge and communicative effectiveness. In J. Galegher \& R. E. Kraut \& C. Egido (Eds.), Intellectual teamwork: Social and technological foundations of cooperative work. Hillsdale, New Jersey: Lawrence Erlbaum Associates. 1990.

Lee, F. Vogel, D. and Limayem, M. "Virtual Community Informatics: A Review and Research Agenda," Journal of Information Technology Theory and Application (JITTA), 5(1), 47-62. 2003.

Lipnack J. and J. Stamps, Virtual Teams: Reaching Across Space, Time and Organizations with Technology. John Wiley and Sons. 1997.

Meadows, C. J. "Globalizing Software Development". Journal of Global Information Management, 4(1), 5-14. 1996.

Nunamaker, J.; Dennis, A.; and Valacich, J. and Vogel, D., "Information Technology for Negotiating Groups: Generating Options for Mutual Gain," Management Science, 37(10): 1325-1346. 1991.

Orlikowski, J. W.; Yates, J.; Okamura, K.; and Fujimoto, M. "Shaping Electronic Communication: The Metastructuring of Technology Context of Use". Organization Science. 6(4), 423-444. 1995.

Paré, Guy and Dubé, Line "Virtual Teams: An Exploratory Study of Key Challenges and Strategies", Proceedings of the $20^{\text {th }}$ International Conference on Information Systems, 479-483. 1999.

Pereira Klen A. A., Rabelo, J. Ricardo, Ferreira, Campos Aureo and Spinosa, Marcio, Luiz. "Managing Distributed Business Processes in the Virtual Enterprise", Journal of Intelligent Manufacturing; 12(2), 185-197. 2001.

Perin, C. "Electronic Social Fields in Bureaucracies". Communications of the ACM. 34(12):75-82. 1991.

Powell A., Piccoli G., and B. Ives, "Virtual Teams: A Review of Current Literature and Directions for Future Research", The DATA BASE for Advances in Information Systems, 35(1), 6-36. 2004.

Qureshi, S., "Supporting a Network Way of Working on an Electronic Social Space." Group Decision and Negotiation. 7:399-416. 1998.

Qureshi S., and D. Vogel. "Organizational Adaptiveness in Virtual Teams". Group Decision and Negotiation. 10(1), 27-46 2001.

Rutkowski, A. F., Vogel, D. R., van Genuchten M., Bemelmans, T. and M. Favier "Ecollaboration: The reality of Virtuality" IEEE Transactions on Professional Communication. New York: Dec. 45(4); p. 219. 2002.

Robey D., Khoo H.M. and C. Powers. "Situated Learning in Cross Functional Virtual Teams. " IEEE Transactions on Professional Communication. 42(1). 51-66. 2000.

Sarker, S. and S. Sahay, "Understanding Virtual Team Development: An Interpretive 
Study", Journal of Association for Information Systems, Vol.4, 1-38. 2003.

Saunders, C.; Van Slyke, C. and Vogel, D. "My Time or Yours? Managing Time Visions in Global Virtual Teams," Academy of Management Executive, 18(1), 19-31. 2004.

Schrage, M. Shared Minds: The New Technologies of Collaboration. New York. Random House. 1990.

Strauss, A. and J. Corbin, Basics of Qualitative Research: Techniques and Procedures for Developing Grounded Theory. Thousand Oaks,London:Sage. 1998.

Tractinsky, N. and L. S. Jarvenpaa, "Information Systems Design Decisions in a Global Versus Domestic Context", MIS Quarterly, 4, 507-534. 1995.

Willcocks P, Leslie and Plant, Robert. "How Corporations E-Source: From Business Technology Projects to Value Networks", Information systems Frontiers, 5(2), 175-193. 2003.

Watson M.B. F., Narasimhan, S. and H.S. Rhee, "Communication and coordination in the Virtual Office", Journal of Management Information Systems, 14(4) 17-28. 1998.

Weick, K. E. Making Sense of the Organization. Oxford: Blackwell. 2001.

Zigurs, I. and S. Qureshi. "Managing the Extended Enterprise, Creating Value from Virtual Spaces." In Dickson, G. and G. DeSanctis. Information Technology and the Future Enterprise: New Models for Managers. Prentice Hall. 2001. pp125-143 ISBN 0130178543 


\section{Publications in the Report Series Research* in Management}

\section{ERIM Research Program: "Business Processes, Logistics and Information Systems"}

\section{4}

Smart Pricing: Linking Pricing Decisions with Operational Insights

Moritz Fleischmann, Joseph M. Hall and David F. Pyke

ERS-2004-001-LIS

http://hdl.handle.net/1765/1114

Mobile operators as banks or vice-versa? and: the challenges of Mobile channels for banks

L-F Pau

ERS-2004-015-LIS

http://hdl.handle.net/1765/1163

Simulation-based solution of stochastic mathematical programs with complementarity constraints: Sample-path analysis S. Ilker Birbil, Gül Gürkan and Ovidiu Listeş ERS-2004-016-LIS

http://hdl.handle.net/1765/1164

Combining economic and social goals in the design of production systems by using ergonomics standards Jan Dul, Henk de Vries, Sandra Verschoof, Wietske Eveleens and Albert Feilzer

ERS-2004-020-LIS

http://hdl.handle.net/1765/1200

Factory Gate Pricing: An Analysis of the Dutch Retail Distribution

H.M. le Blanc, F. Cruijssen, H.A. Fleuren, M.B.M. de Koster

ERS-2004-023-LIS

http://hdl.handle.net/1765/1443

A Review Of Design And Control Of Automated Guided Vehicle Systems

Tuan Le-Anh and M.B.M. De Koster

ERS-2004-030-LIS

http://hdl.handle.net/1765/1323

Online Dispatching Rules For Vehicle-Based Internal Transport Systems

Tuan Le-Anh and M.B.M. De Koster

ERS-2004-031-LIS

http://hdl.handle.net/1765/1324

Generalized Fractional Programming With User Interaction

S.I. Birbil, J.B.G. Frenk and S. Zhang

ERS-2004-033-LIS

http://hdl.handle.net/1765/1325

\footnotetext{
* A complete overview of the ERIM Report Series Research in Management: https://ep.eur.nl/handle/1765/1

ERIM Research Programs:

LIS Business Processes, Logistics and Information Systems

ORG Organizing for Performance

MKT Marketing

F\&A Finance and Accounting

STR Strategy and Entrepreneurship
} 
Meta-heuristics for dynamic lot sizing: A review and comparison of solution approaches

Raf Jans and Zeger Degraeve

ERS-2004-042-LIS

http://hdl.handle.net/1765/1336

Reinventing Crew Scheduling At Netherlands Railways

Erwin Abbink, Matteo Fischetti, Leo Kroon, Gerrit Timmer And Michiel Vromans

ERS-2004-046-LIS

http://hdl.handle.net/1765/1427

Intense Collaboration In Globally Distributed Teams: Evolving Patterns Of Dependencies And Coordination

Kuldeep Kumar, Paul C. van Fenema and Mary Ann Von Glinow

ERS-2004-052-LIS

http://hdl.handle.net/1765/1446

The Value Of Information In Reverse Logistics

Michael E. Ketzenberg, Erwin van der Laan and Ruud H. Teunter

ERS-2004-053-LIS

http://hdl.handle.net/1765/1447

Cargo Revenue Management: Bid-Prices For A 0-1 Multi Knapsack Problem

Kevin Pak and Rommert Dekker

ERS-2004-055-LIS

A Grounded Theory Analysis Of E-Collaboration Effects For Distributed Project Management

S. Qureshi, M. Liu and D. Vogel

ERS-2004-059-LIS 